\title{
Modeling and Control Maximum Power Point Tracking of an Autonomous Photovoltaic System Using Artificial Intelligence
}

\author{
Amadou Fousseyni Toure ${ }^{1,2}$, David Tchoffa ${ }^{1}$, Abderrahman El Mhamedi1 ${ }^{*}$, Badie Diourte ${ }^{2}$, \\ Myriam Lamolle ${ }^{1}$ \\ ${ }^{1}$ Equipe MGSI, laboratoire Quartz, IUT de Montreuil, Montreuil, France \\ ${ }^{2}$ Faculté des Sciences et Techniques de Bamako, Université des Sciences, des Tecthniques et des Technologies de Bamako \\ (USTTB), Bamako, Mali \\ Email: d.tchoffa@iut.univ-paris8.fr, amadatoure@yahoo.fr, *a.elmhamedi@iut.univ-paris8.fr
}

How to cite this paper: Toure, A.F., Tchoffa, D., El Mhamedi, A., Diourte, B. and Lamolle, M. (2021) Modeling and Control Maximum Power Point Tracking of an Autonomous Photovoltaic System Using Artificial Intelligence. Energy and Power Engineering, 13, 428-447. https://doi.org/10.4236/epe.2021.1312030

Received: October 19, 2021

Accepted: December 27, 2021

Published: December 30, 2021

Copyright $\odot 2021$ by author(s) and Scientific Research Publishing Inc. This work is licensed under the Creative Commons Attribution International License (CC BY 4.0).

http://creativecommons.org/licenses/by/4.0/

\begin{abstract}
Despite investigative efforts seen in the literature, the maximum power point tracking remains again a crucial problem in photovoltaic system (PV) connected to the power grid. In this paper, a new maximum power point tracking technique which is our contribution to the resolution of this problem is treated. We proposed a hybrid controller of maximum power point tracking based on artificial neural networks. This hybrid controller is composed of two neural networks. The first network has two inputs and two outputs: the inputs are solar irradiation and ambient temperature and the outputs are the reference output voltage and current corresponding at the maximum power point. The second network has two inputs and one output: the inputs use the outputs of the first network and the output will be the periodic cycle which controls the DC/DC converter. The training step of neural networks requires two modes: the offline mode and the online mode. The data necessary for the training are collected from a very large number of real-time measurements of the PV module. The performance of the proposed method is analyzed under different operating conditions using the Matlab/Simulink simulation tool. A comparative study between the proposed method and the perturbation and observation approach was presented.
\end{abstract}

\section{Keywords}

PV System, MPPT Controller, Artificial Neural Networks, Matlab/Simulink

\section{Introduction}

Knowing that the ratio "Power supplied to the output per unit of PV generator" 
is relatively low and the cost of acquiring PV modules relatively high, then it is important to look into the question of the efficiency of these PVs from on the one hand, and on the other hand on reducing the cost of energy production. Regarding efficiency, power electronics systems (with passive components) are responsible for most of the energy loss in the entire PV system. The possibilities for achieving the efficiency demanded involve the use of advanced semiconductor materials, intelligent control systems and PV technologies without loss of power. As shown in Figure 1, better monitoring, forecasting and communication technologies will also be crucial for the siting of future grid-connected PV systems.

The downside to solar power generation is that the power generation is not constant throughout the day, as it changes with climatic conditions [1]. In addition, the conversion efficiency of solar energy to electric energy is very low which is only in the order of $9 \%$ to $17 \%$ in low irradiation regions [2]. Despite its simple shape, the operating point oscillates around the MPP (Maximum Power Point) which causes energy loss and long tracking time. In addition, depending on variations in climatic conditions (solar irradiation and ambient temperature), the operating point moves on another curve [3]. This leads to failures in MPP monitoring, as for example, the algorithm is unable to identify the source of disturbance from voltage variation or weather conditions.

The perturbation and observation $(\mathrm{P} \& \mathrm{O})$ technique also requires a control process system (such as software), which makes it challenging to integrate it into the PV panel [4]. An incremental conductance (InC) MPPT algorithm improving the $\mathrm{P} \& \mathrm{O}$ technique is presented in [5]. A modification of this InC algorithm, employing a dynamic adaptation of the number of steps during the tracking process is proposed [6]. In [7], it has demonstrated through experimental tests that the $\mathrm{P} \& \mathrm{O}$ and InC methods have similar performance under static and dynamic conditions.

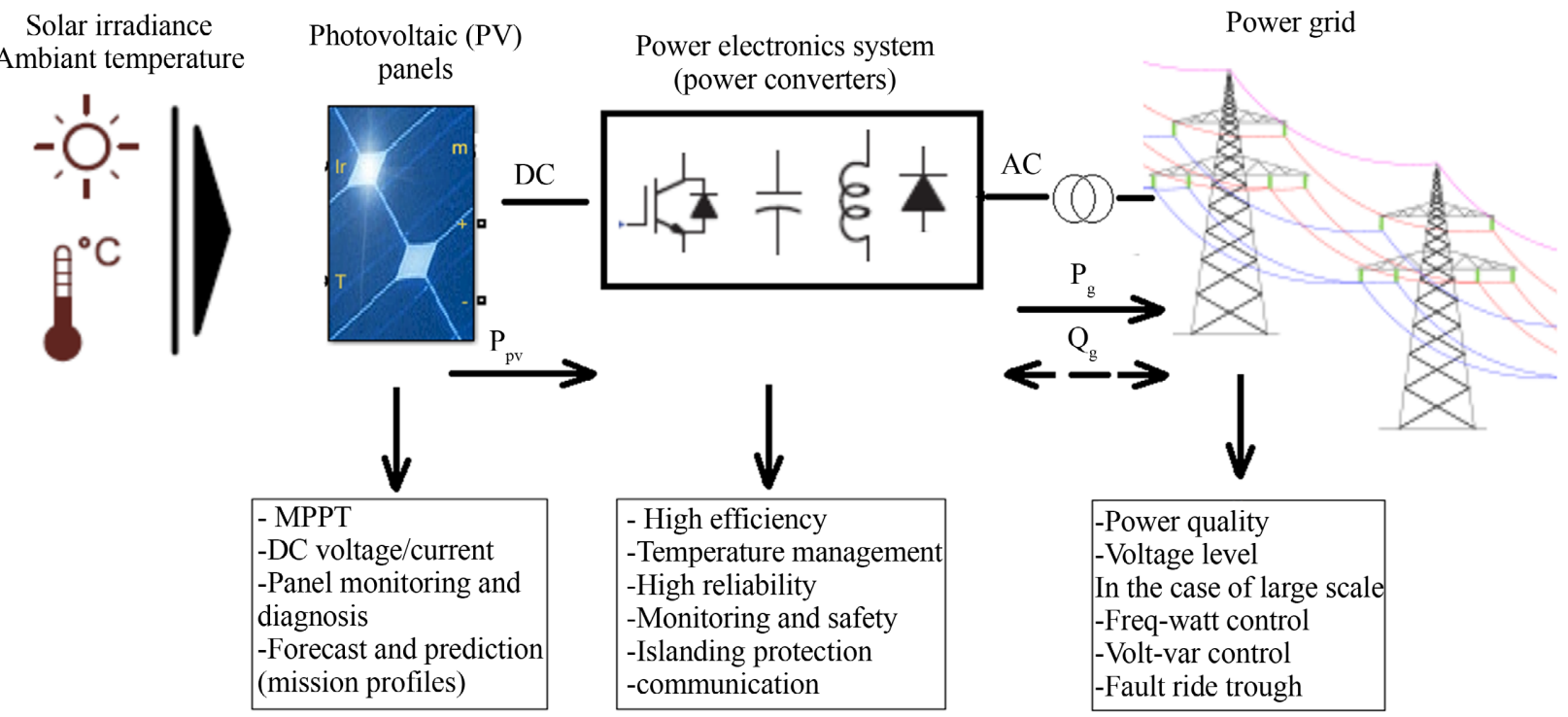

Figure 1. Recommended reliability at the levels of different parts of the grid-coupled PV system. 
The voltage-constant and current-constant methods also require a voltage and current sensor respectively for their implementation, but the periodic interruption of the operation of the PV source to measure the no-load voltage and the short-circuit current results loss of energy [8]. Using artificial intelligence techniques, the accuracy of predicting voltage and current at the PPM is strongly affected by the accuracy of estimating the temperature of PV modules, which affects the values of $\mathrm{Vt}$ and Is [9]. The implementation of digital techniques is complex and given the complexity of the calculations of the voltage or current MPP, a microcontroller or a DSP unit is necessary for the realization of such an MPPT system. In addition, the response time of the MPP tracking algorithm is relatively low [10]. To avoid the use of a derivative to perform the MPPT process, the tangent of the power-voltage curve, $\frac{\partial P_{p v}}{\partial V_{p v}}$ used in the $\mathrm{P} \& \mathrm{O}$ technique to detect the MPP, is replaced in the Ripple Correlation Control (RCC) method MPPT by a correlation function, the performance of the RCC MPPT technique is affected by the accuracy of the measurements of the correlation function $c(t)$ [11] [12]. The Maximum Seek Control (ESC) method which has a self-optimization strategy, operates on a similar basic principle that RCC MPPT, it has the disadvantage that for its realization in the PV power processing system, the development of a relatively complex control circuit is necessary [13] [14].

Despite investigative efforts seen in the literature the maximum power point tracking still remains a crucial problem in the grid connected PV system.

In this work, we propose a hybrid MPPT controller based on the artificial neural network to improve the failures mentioned above. The hybrid MPPT is composed of two neural networks, the first network has two inputs and two outputs; inputs are solar irradiation and ambient temperature and outputs are reference output voltage and current. The second network has two inputs and one output; the inputs use the outputs of the first network and the output will be the periodic cycle which controls the DC/DC converter (Figure 14). The data necessary for the generation of the RNA (Artificial Neuron Network) model are obtained from the series of measurements. The networks are developed in two modes: the offline mode to obtain the optimal structure, activation function and learning algorithm of neural networks and the online mode where these optimal RNA MPPT controllers are used in the PV system. The proposed MPPT neural network controller is tested and validated using the Matlab/Simulink modeling and simulation tool under different conditions of climatic variation, which is directly equipped with an Artificial Neural Networks toolbox.

\section{Materials and Methods}

\subsection{Modeling of a Photovoltaic Module under Matlab/Simulink}

The basic structure of a PV cell can be modeled as basic electrical components [15]. Figure 2 shows the PN semiconductor junction and the different components that make up a PV cell. The photon-electron circulation process can be 


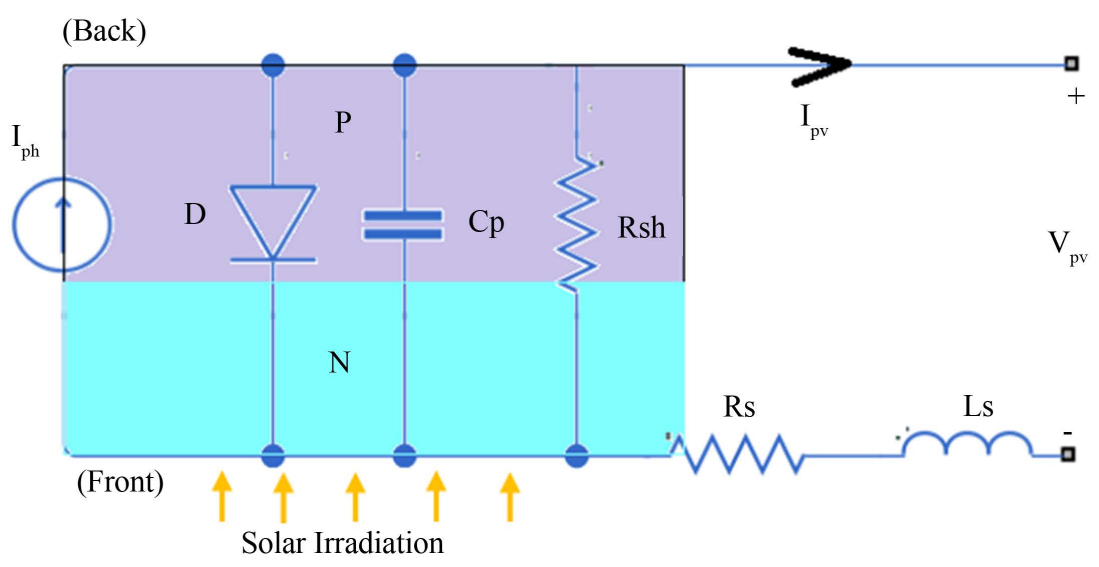

Figure 2. Model of a basic structure of a PV cell.

modeled as a current source Iph, where the current generated depends on the light intensity hitting the cell. The PN semiconductor junction is modeled as a diode $\mathrm{D}$, with the direction shown in Figure 2.

The current source and the diode are an ideal model of a PV cell, but in reality, there are additional parasitic components. The PN junction is mounted in parallel with a parallel capacitance $\mathrm{Cp}$ and a parallel resistor Rsh (also called shunt resistor), whereas the wires of conduct connected to the PV cell are associated with a series resistor Rs, and inductance in series Ls. These parasitic components are often ignored when a simple representation of a PV cell or panel is necessary, but they must be taken into account when precise modeling is recommended.

The simple PV model can be implemented under Matlab/Simulink as illustrated in Figure 3, where the inputs are solar irradiation G, ambient temperature $\mathrm{T}$ and voltage of $\mathrm{PV}(\mathrm{Vin})$. The outputs are the current intensity of $\mathrm{PV}\left(\mathrm{I}_{\mathrm{PV}}\right)$ and the power $\left(\mathrm{P}_{\mathrm{PV}}\right)$. We did a simulation under Matlab/Simulink. The curve of the intensity of the PV module depending on the voltage of the PV module as well as the curve of the power of the PV module as a function of the voltage of the PV module is shown in Figure 4 and Figure 5 respectively.

The star indicates the maximum power point, where the PV module will produce its maximum power. For a voltage lower than that of the MPP, the current is relatively constant when the voltage varies in the same way as a current source. For a voltage higher than that of the MPP, the voltage is relatively constant when the current varies as a voltage source. The open circuit voltage $\left(\mathrm{V}_{\mathrm{OC}}\right)$ is the $\mathrm{PV}$ voltage when the current is zero $(0 \mathrm{~A})$ and the short-circuit current $\left(\mathrm{I}_{\mathrm{SC}}\right)$ is the current which corresponds to a zero voltage.

The current-voltage and power-voltage curves in Figure 4 and Figure 5 are under a specific condition of solar irradiation and of ambient temperature. During the day, the two curves can sometimes vary gradually (minutes to hours) and sometimes very quickly (seconds), due to the passages of clouds.

As the irradiation and the ambient temperature vary, the curve of I - V characteristic also varies as shown in Figure 6. The irradiation is directly proportional 


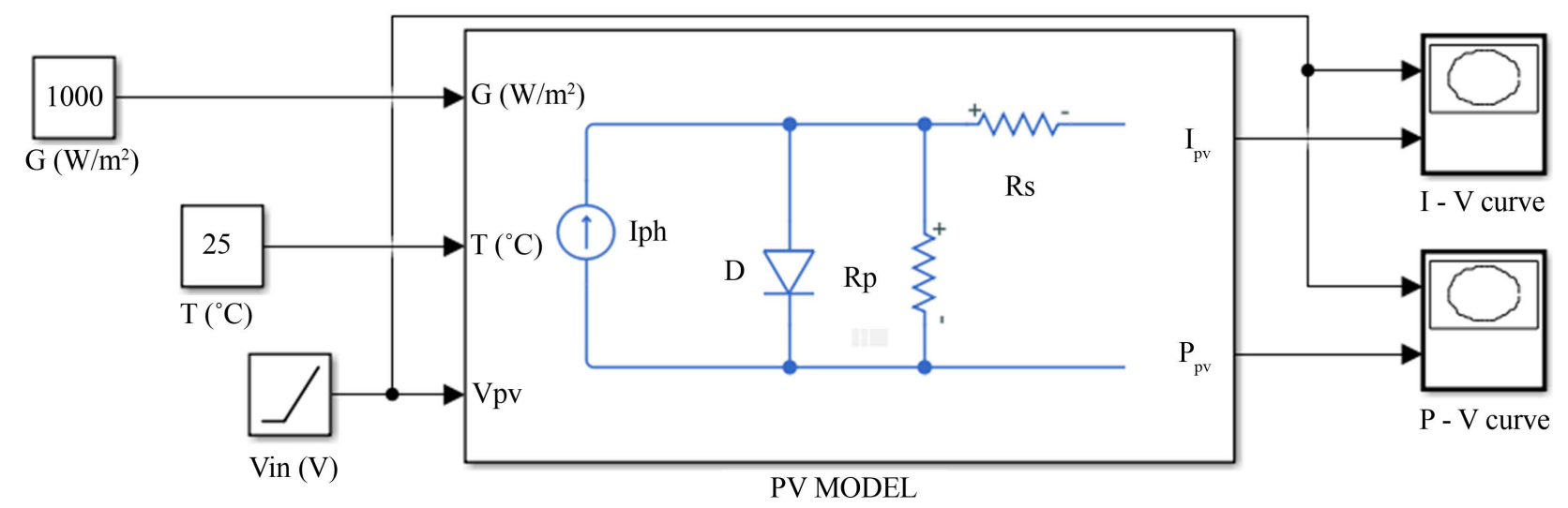

Figure 3. Model of a PV cell with solar irradiation, temperature and voltage as inputs.

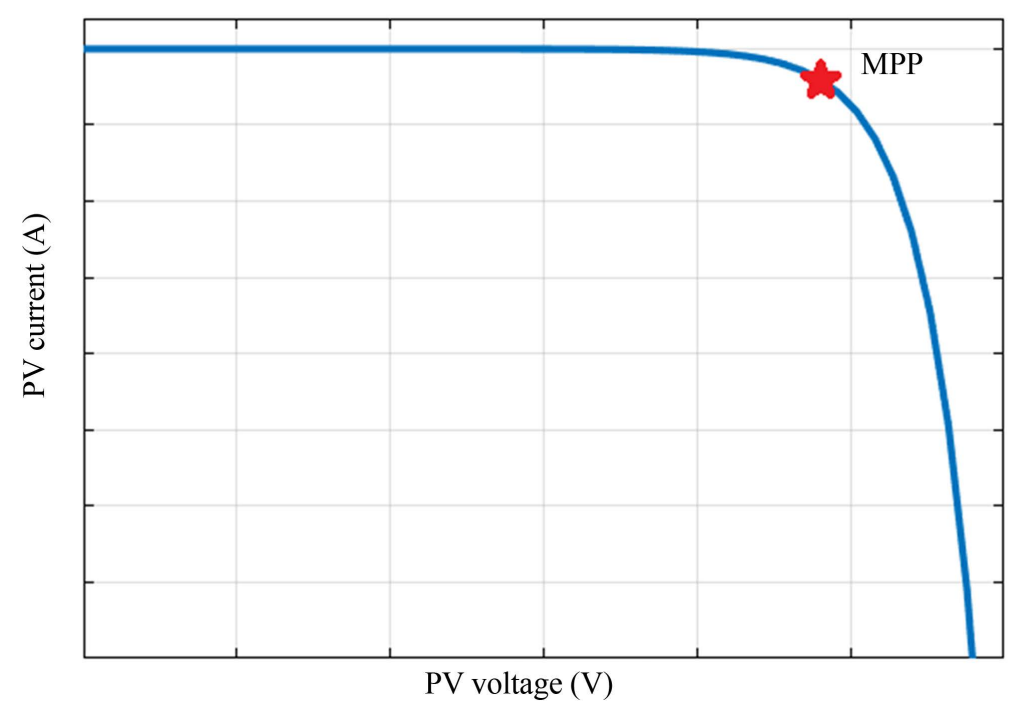

Figure 4. The intensity curve as a function of the voltage of an example of a PV cell under standard conditions $\left(\mathrm{G}=1000 \mathrm{~W} / \mathrm{m}^{2}\right.$ and $\left.\mathrm{T}=25^{\circ} \mathrm{C}\right)$.

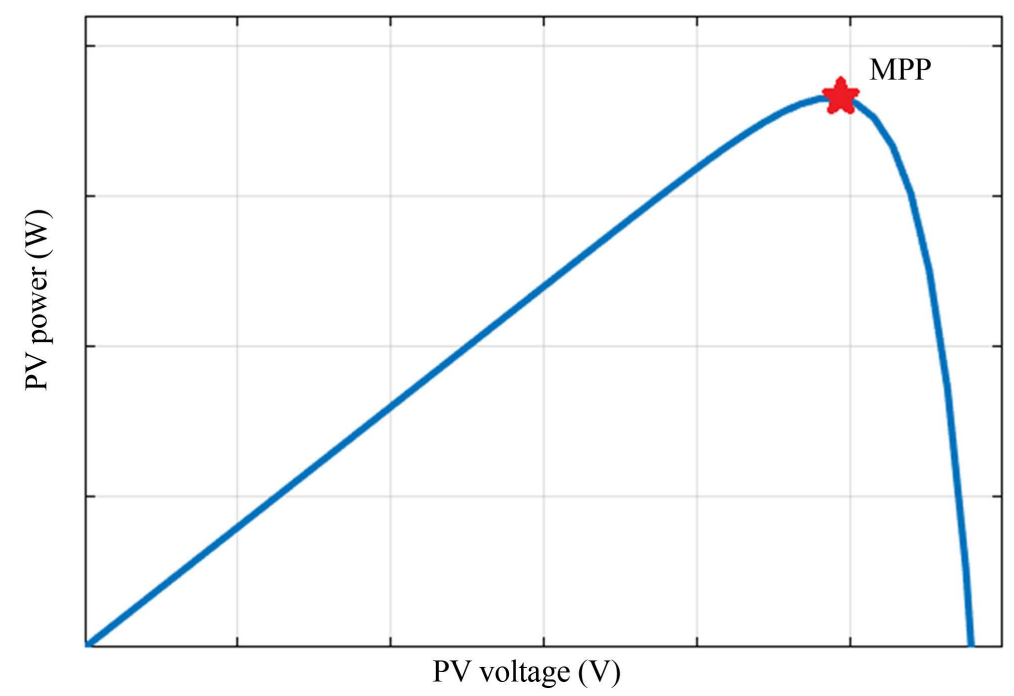

Figure 5. The power curve as a function of the voltage of an example of a PV cell under standard conditions $\left(\mathrm{G}=1000 \mathrm{~W} / \mathrm{m}^{2}\right.$ and $\left.\mathrm{T}=25^{\circ} \mathrm{C}\right)$. 


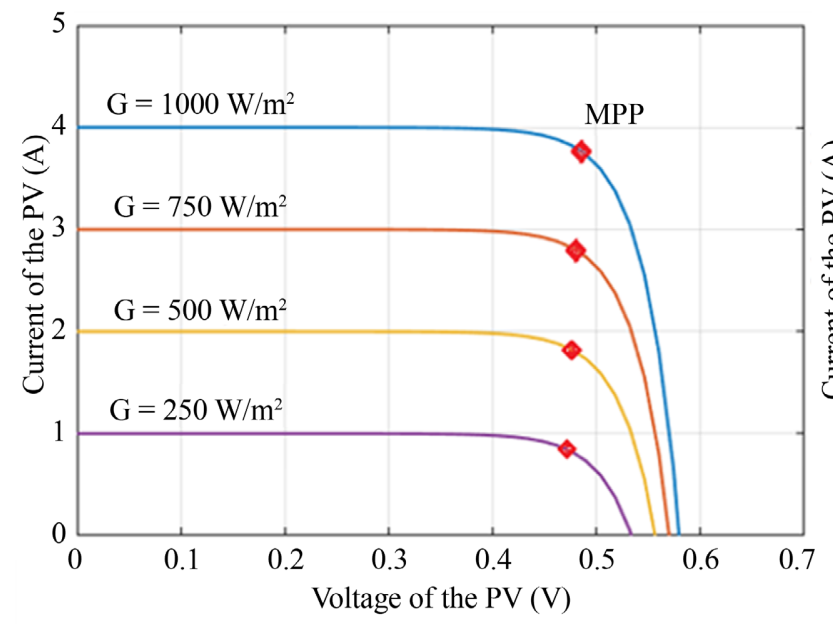

(a)

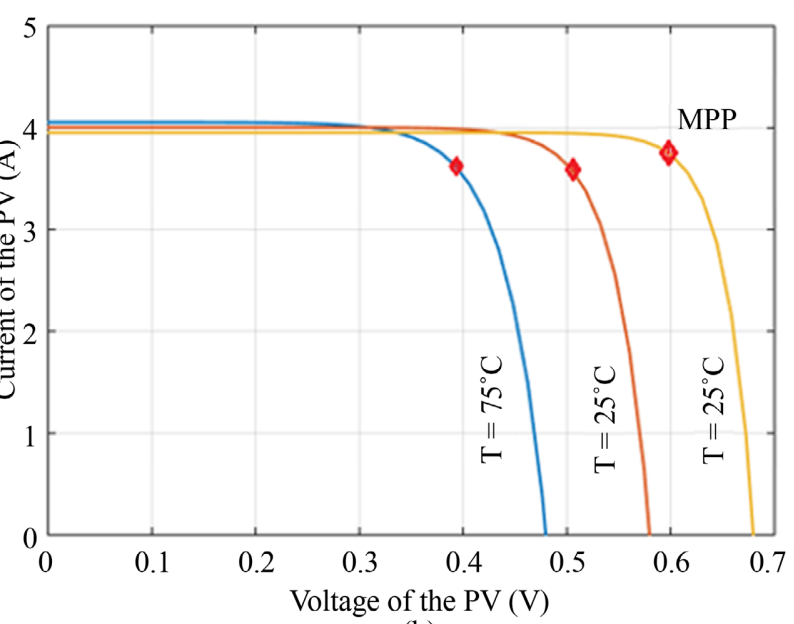

(b)

Figure 6. The dependence curves of the efficiency of a solar cell to variations in climatic conditions [16].

to the currents of the characteristic. When the irradiation increases the short-circuit current and the current of the maximum power point also increases; the temperature is inversely proportional to the voltages of the characteristic. When the temperature increases, the open circuit voltage and the voltage at the maximum power point decrease. According to these trends, a PV cell will produce more energy when the light intensity is high and the temperature is low. However, these kinds of environmental conditions are not common, when a greater light intensity hits an object its temperature tends to increase at the same time.

\subsection{Maximum Power Point Tracking (MPPT) Methods Operating under the Conditions of Varying Mission Profiles (Solar Irradiation and Ambient Temperature)}

Due to short and long variations in solar irradiation and ambient temperature, the position of the MPP (Maximum Power Point) changes. Therefore, the application of an MPPT control algorithm is required, and ensures to continuously converge the operating point around the MPP of a PV source so as to optimize the power output of the PV system. Several tracking control techniques have been developed and applied in the literature. The most frequently used MPPT algorithms are the hill-climbing methods, such as Perturbation and Observation $\mathrm{P} \& \mathrm{O}$ and its other implementations (with identical behavior), incremental conductance. These methods are based on the fact that at the level of the voltage-power characteristic, the ratio of the variation of the power and the voltage is positive $\left(\frac{\Delta P}{\Delta V}>0\right.$ in the left part of the MPP, while it is negative $\left(\frac{\Delta P}{\Delta V}<0\right.$ in the right part of the MPP as shown in Figure 7 [16].

The main advantages of these methods are that 1) they are generic, they are suitable for all PV modules, 2) they do not ask for PV information, 3) they work well under most conditions and 4) they are simple to perform in a controller digital with less computation required. However, these methods have some 


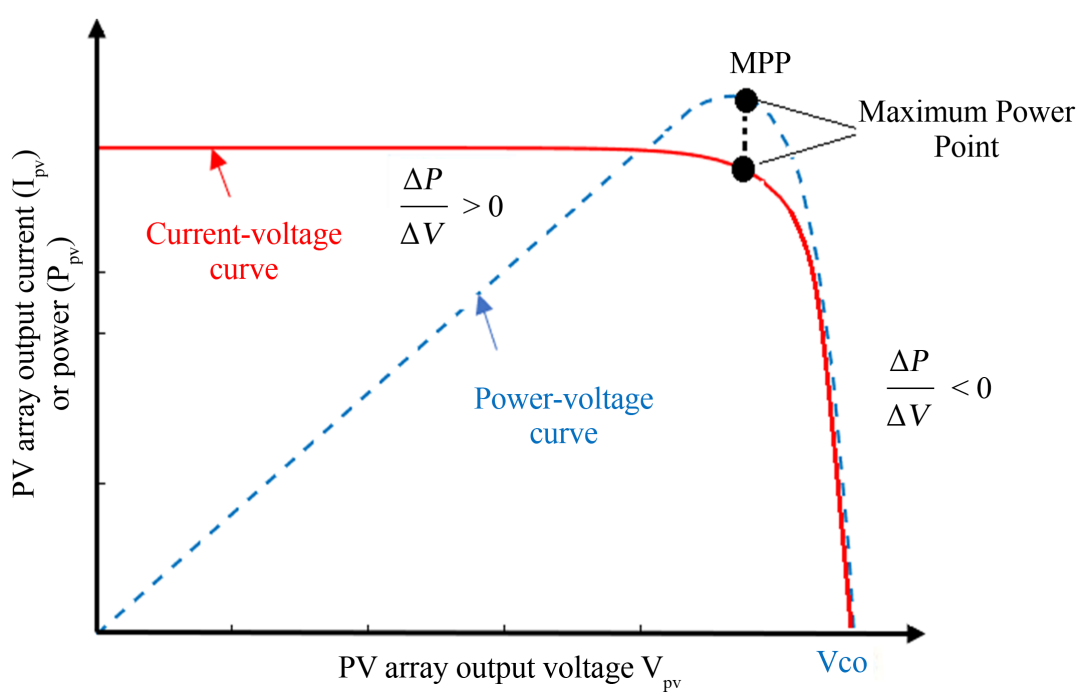

Figure 7. Current/voltage and power/voltage characteristic of a photovoltaic module.

fundamental flaws because they are limited in the ability to follow during the conditions of variations and in the case of the partial shade, they cannot provide the global MPP stabilized at the level of the maximum point on the curve voltage-power.

These failures have inspired many publications that aim to overcome these problems. The advanced MPPT methods most widely used in the literature are based on fuzzy logic [17], neural networks [18], genetic algorithms and particle swarm optimization [19], etc.

\subsubsection{MPPT Perturbation and Observation Technique (P\&0)}

The perturbation and observation method ( $\mathrm{P} \& \mathrm{O}$ MPPT) is based on the property, that the derivative of the power-voltage characteristic of the PV module/array is positive to the left of the MPP, negative to the right and zero at the MPP point [18].

$$
\frac{\partial P_{p v}}{\partial V_{p v}}=0
$$

where $P_{p v}$ and $V_{p v}$ are respectively the output power and voltage of the PV module/array.

During the execution of the $\mathrm{P} \& \mathrm{O}$ MPPT process, the output voltage and current of the PV module/array are periodically taken to calculate the PV output power and the reference voltage. The process is performed by adjusting the reference signal of the converter's PWM controller, $V_{\text {ref }}$ based on the sign of $\frac{\partial P_{p v}}{\partial V_{p v}}$, according to the following equation [18]:

$$
V_{\text {ref }}(k)=V_{\text {ref }}(k-1)+\alpha \operatorname{sign}\left(\frac{\partial P_{p v}}{\partial V_{p v}}(k)\right)
$$

where $k$ and $k-1$ are the consecutive times, $\alpha>0$ is a constant determining the 
speed of convergence of the MPP, and the function $\operatorname{sign}(x)$ is defined as the following [18]:

$$
\operatorname{sign}(x)= \begin{cases}1 & \text { si } x>0 \\ -1 & \text { si } x<0\end{cases}
$$

The output voltage of the PV module/array is regulated to the desired value $V_{r e f}$ according to the equation $V_{r e f}(k)$, using either a (proportional integral PI) or for example a fuzzy logic controller. The latter has the advantage of providing a better response under dynamic conditions [20].

Under static state conditions, the operating point of the PV module/array oscillates around the MPP point with an amplitude determined by the value of $\alpha$ in Equation (2) of $V_{\text {ref }}$ Increasing the perturbation step allows faster convergence to the MPP under changing conditions of solar irradiation and/or ambient temperature but increases permanent oscillations around the MPP, thus resulting in losses in the device. A MPPT system based on the P\&O method can be developed either by setting up the $V_{\text {ref }}$ equation in the form of an algorithm and executed by a microcontroller or a digital signal processing device DSP (Digital Signal Processing) or using mixed-signal circuits. A structure of the algorithm based on the P\&O MPPT procedure proposed in [21] is presented in Figure 8 below. The process is repeated until the gradient value $\frac{\partial P_{p v}}{\partial V_{p v}}$ is less than the preset threshold value, indicating that the convergence of the MPP is almost achieved with the desired precision.

A methodology for the design of the control unit such as the operating processes of P\&O MPPT with the optimal values of the step of progression and the period of disturbance is proposed in [22]. An algorithm to dynamically adapt the number of perturbations according to the conditions of solar irradiation is proposed in [23] to increase the response step of the $\mathrm{P} \& \mathrm{O}$ algorithm and reduce

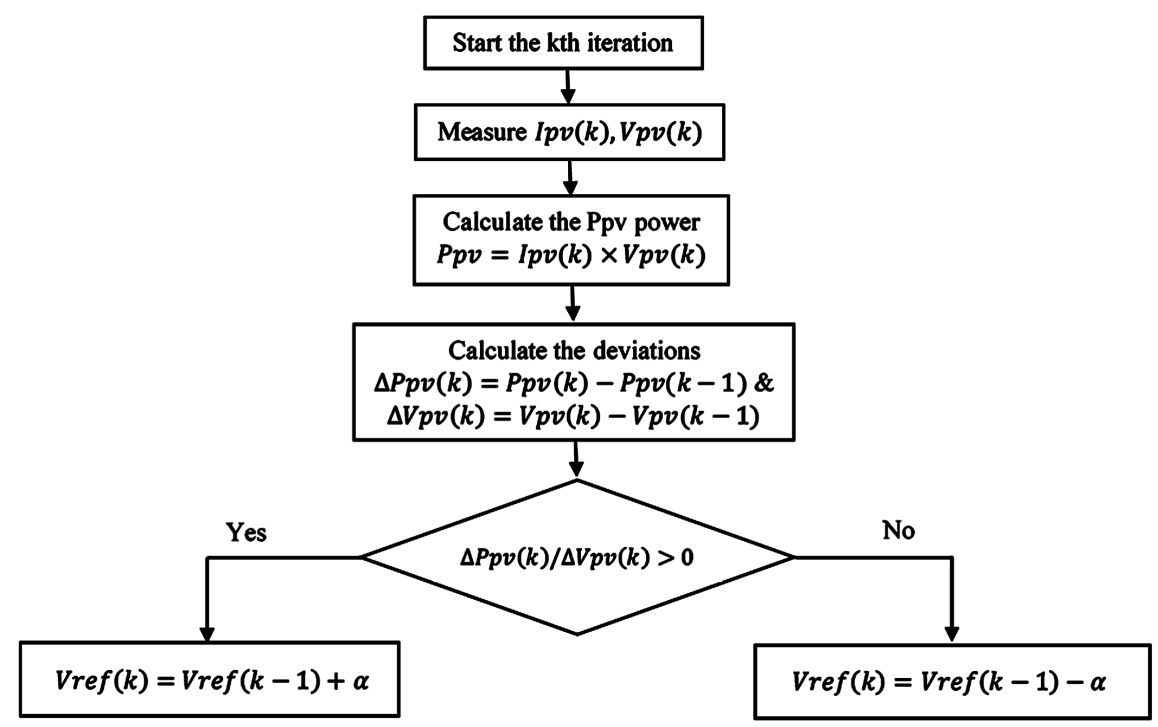

Figure 8. A structure based on the perturbation technique and observation $\mathrm{P} \& \mathrm{O}$. 
the permanent oscillation around the MPP.

Despite its simple shape, the operating point oscillates around the MPP which causes energy loss and long tracking time. In addition, depending on variations in climatic condition (solar irradiation and ambient temperature), the operating point moves on another curve.

These failures generated in MPP tracking such as the algorithm is unable to identify the source of disturbance from voltage variation or weather conditions. The $\mathrm{P} \& \mathrm{O}$ also requires a process control system (like software) which makes it difficult to integrate on the PV panel. A wait function causes the temporary disturbance to stop, if the perturbation sign is changed, indicating that MPP is suggested to be searched. This method reduces the oscillation around the MPP but it makes the MPPT slower to respond to conditions of atmospheric change. The oscillation around was reduced by using the number of dynamic steps of the perturbation which deviate smaller around the PPM. MPPT becomes fast and precise.

\subsubsection{Techniques Based on MPPT Artificial Intelligence}

Artificial intelligence techniques such as neural network and fuzzy logic are also well applied to perform the MPPT process. An artificial neural network is a computer model inspired by the biological neural network. In such a model, a neuron is a processing unit that first linearly weighs the inputs, then works out the sum with a non-linear function, called an activation function (AF), and finally sends the results to the following neurons Figure 9. The model of a common neuron is given by Equation (5), where $Z$ is the argument of AF.

$$
Z=\sum_{m=1}^{M} W_{m} X_{m}+\alpha
$$

where $X_{1}, X_{2}, \cdots, X_{m}$ are the $m$ incoming signals, and $W_{1}, W_{2}, \cdots, W_{m}$ are the associated weights.

$$
y=\frac{1}{1+\mathrm{e}^{-Z}}
$$

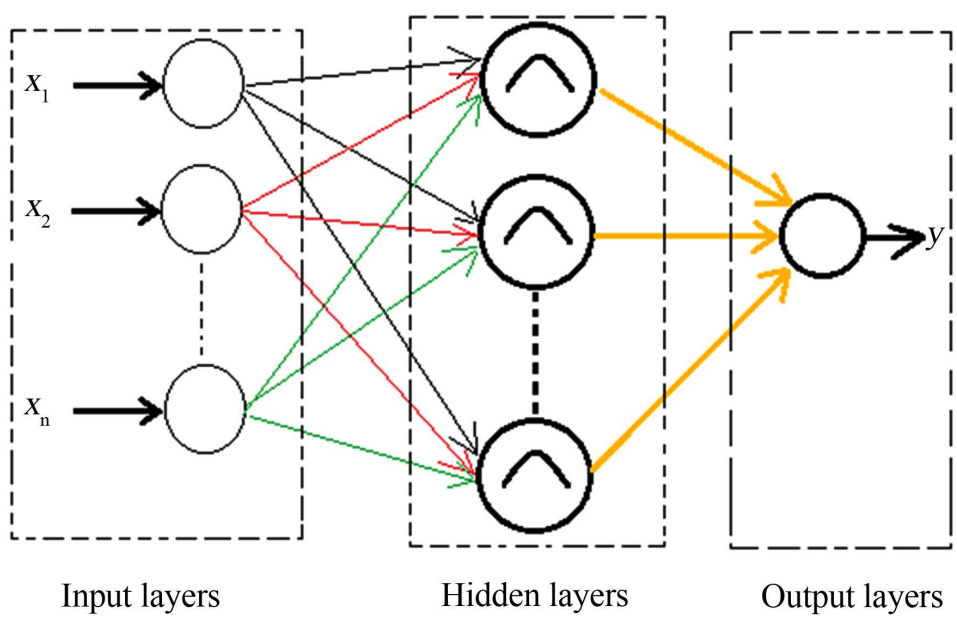

Figure 9. Multilayer feedback neural network. 
A large number of training processes are available, but it is the retro-propagation method that is the best known and the most used. The training of the algorithm consists in minimizing the total error $E$ defined by the following equation [24]:

$$
E=\frac{1}{2} \sum\left(O_{n}-t_{n}\right)^{n}
$$

where $O_{n}$ is the $n$th measurement read at the output of the network and $t_{n}$ is the nth target (the estimated output).

So, each input/output pair constitutes a sample. The back-propagation algorithm calculates the error $E$ and distributes the return of the output to the input neurons through the hidden neurons using the equation [24]:

$$
\Delta w_{n}=\delta \Delta w_{n}-\eta \frac{\partial E}{\partial w}
$$

where $w$ is the weight between two neurons, $\Delta w_{n}$ and $\Delta w_{(n-1)}$ are the variations of these weights for $n$ and $n-1$ iterations, $\delta$ is the duration of the regime and $\eta$ is the training rate. The training rate determines the number of weight changes caused by the effect of total error.

The number of neurons selected in the hidden layer determines the degree of training. This number is calculated by the following empirical formula [24]:

$$
N_{h}=\frac{1}{2}\left(N_{1}+N_{0}\right)+\sqrt{N_{E}}
$$

where $N_{h}$ is the number of neurons, $N_{1}$ is the number of input neurons, $N_{0}$ is the number of output neurons, and $N_{E}$ is the number samples of training. In order to ensure network accuracy, the training sample is continuously adjusted after each training by passing all test data to the trained ANN model and the results recorded.

Then it is compared to the measurements. In case of convergence, the performance of the network is reproduced by calculating the performance factor. Data validation is used as an additional check on model performance. If the performance of the network is quite correct on the sample and validation test, we can consider that the network is good enough to generate a fair periodic cycle.

\subsection{Comparison of MPPT Techniques for Varying Conditions of Solar Irradiation}

A comparison of the functional characteristics of the above MPPT methods is presented in Table 1. The $\mathrm{P} \& \mathrm{O}, \mathrm{InC}$ and simple MPPT sensor approach are characterized by simple implementation and have similar static and dynamic performance.

Despite this, their operation can be affected by external disturbances (for example, the short term and rapid change of the metrological conditions), they are able to pursue the point of maximum power. Constant voltage, constant current, and artificial intelligence-based methods are more robust compared to $\mathrm{P} \& \mathrm{O}$ and InC methods, and they are less affected by external disturbances. However, 
Table 1. Comparison of functional characteristics of the MPPT methods.

\begin{tabular}{|c|c|c|c|c|c|c|}
\hline & & & & Robust & hess & \\
\hline MPPT $\mathrm{n}$ & hod & $\begin{array}{c}\text { Sampling } \\
\text { rate }\end{array}$ & Complexity & $\begin{array}{l}\text { To external } \\
\text { disturbances }\end{array}$ & $\begin{array}{c}\text { Aging } \\
\text { of PV } \\
\text { modules }\end{array}$ & Efficiency \\
\hline $\begin{array}{r}\text { Cons } \\
\text { voltage/c } \\
\text { curr }\end{array}$ & stant & - & + & - & - & - \\
\hline P\& & & + & + & - & + & + \\
\hline $\operatorname{In}$ & & + & + & - & + & + \\
\hline Model & sed & + & - & + & - & - \\
\hline Artificial & ANN & + & - & + & - & - \\
\hline intelligence & FLC & + & - & + & + & - \\
\hline Single s & sor & + & + & + & + & - \\
\hline $\begin{array}{r}\text { Multiph } \\
\text { parabolic } \mathrm{p}\end{array}$ & $\begin{array}{l}\text { and } \\
\text { diction }\end{array}$ & + & - & + & + & + \\
\hline $\begin{array}{l}\text { Other c } \\
\text { optimiz }\end{array}$ & $\begin{array}{l}\text { ital } \\
\text { ons }\end{array}$ & - & - & + & + & + \\
\hline $\mathrm{RC}$ & & + & - & - & + & + \\
\hline ES & & + & - & + & + & + \\
\hline $\begin{array}{l}\text { Adjus } \\
\text { mode } \mathrm{c}\end{array}$ & $\begin{array}{l}\text { le } \\
\text { trol }\end{array}$ & + & + & + & - & + \\
\hline
\end{tabular}

their efficiencies are dependent on the periodic interruption of the PV source for measurements of the open circuit voltage Voc and the short circuit current of the PV source. The efficiency is further reduced with the precision of the knowledge of the functional parameters of the PV source, which is necessary for their implementation. In digital MPPT optimization algorithms, a scanning process is periodically repeated to detect possible changes in the position of the MPP, which results in a reduction in its efficiency due to the losses of energy generated until the convergence at MPP point, is performed. Numerical algorithms do not require specific knowledge of the system for their applications, but the complexity of their implementations is higher than for those of $\mathrm{P} \& \mathrm{O}$ and InC methods. The robustness of these numerical techniques is affected by external disturbances, so they are not able to consider the estimation errors, which arise from the decisions made during each iteration, until a new scanning process is carried out.

The robustness of the RCC technique can easily be affected by the impact of external variations on the computational accuracy of the correlation function. In addition, a suitable consistent design of the power converter and MPPT controller is required for the implementation of our RCC MPPT method, thus requiring the availability of system knowledge. The complexity of the control circuit of 
RCC and ESC MPPT techniques is relatively high. The ESC method is more robust than that of the RCC. However, a detailed knowledge of the functional characteristics of the PV system is necessary by the ESC method for learning the functional parameters of the control loop.

\subsection{Modeling Approach of a Hybrid MPPT from the Artificial Neuron Network}

\subsubsection{MPPT Technique Based on Artificial Neuron Network}

The architecture of the adapted neural network consists of three layers. The input layers made up of two neurons like we have two inputs (solar irradiation and ambient temperature). The hidden layers, including $\mathrm{n}$ neurons; this number is selected following the execution of rules of thumb starting with a large number of neurons and eliminating unnecessary ones provided that a stable network and precise output are sought. The output layer contains a neuron that corresponds to the optimal periodic cycle. First, measurements of solar irradiation and ambient temperature are fed into an artificial neural network (ANN) and the corresponding optimum value of the operating cycle (periodic cycle) of the DC/DC converter is estimated, a structure is presented (see Figure 10) [22]. In order to obtain accurate results, the ANN should be trained using prior quantitative measurements in real-time operation in the MPPT tracker unit, which is a disadvantage.

The values of the connection weights and the ANN thresholds are selected randomly at the start of the training process and then during the training they are set in order to minimize the difference between the estimated and formed data.

An ANN is a massively distributed parallel processor that has a natural tendency to store experimental knowledge and make it available for use. The power of RNAs in the identification and development system of adaptive controllers makes them well suited for PV system applications such as PV module MPPT maximum power point tracking. A non-recurring multilayer network has been developed to calculate the optimal DC/DC periodic cycle considering variations in solar irradiation and ambient temperature.

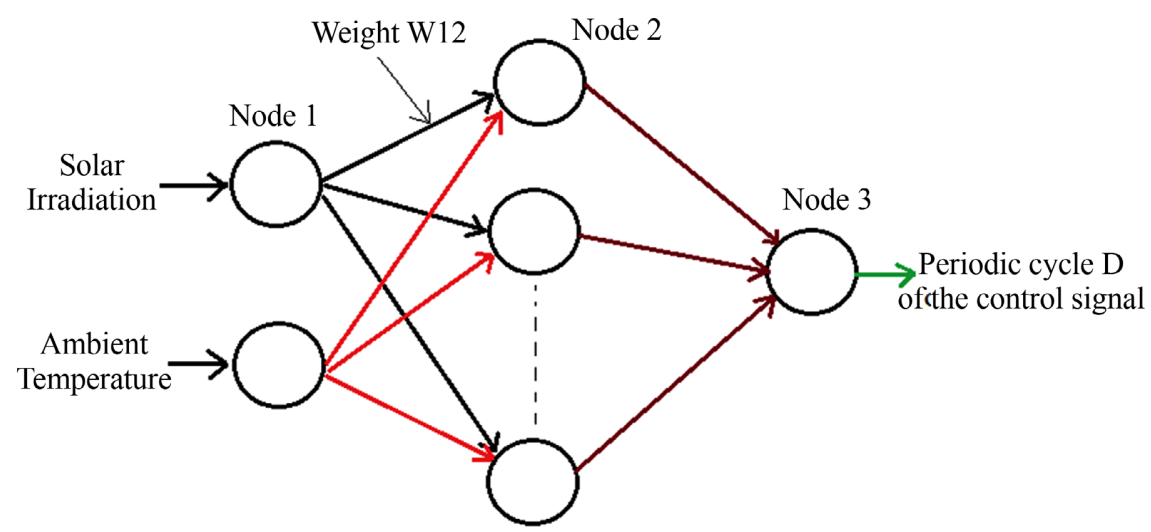

Figure 10. A structure of the technique based on Artificial Neural Networks (ANN). 


\subsubsection{Hybrid Model of Artificial Neuron Network}

Based on the analysis of Table 1, we proposed to hybridize the different techniques in order to have a robust MPP tracking approach to external disturbances. We first use a set of solar irradiation and ambient temperature samples or data from the PV module datasheet to train the neural networks. We used data over the period of one year collected from renewable energy agency of Mali. This database included the irradiation, temperature, voltage and current values of PV modules and we calculated the corresponding periodic cycles. The measurements were taken hourly for a year, a sample number of 8760 used for training our neural networks.

The formation of the networks follows the following steps: the first step consists of injecting the data into the networks, then calculating the objective functions (e.g., periodic cycle). If the best solution is reached, another technique will be used to control the conversion system in order to pursue the point of maximum power. This technique can be either, the perturbation and observation method, conduction by incrementation, fuzzy logic or artificial neural network. In our study case we used the artificial neural network method. Figure 11 illustrates the structure of our proposed approach.

\subsubsection{Training of Neural Networks}

In this work, the backpropagation ANN composed of three hidden layers is used with logsig activation functions. This optimal number of the hidden layer is obtained on a heuristic basis so that the accuracy of the prediction is acceptable. As mentioned earlier, training neural networks requires two modes: offline mode and online mode.

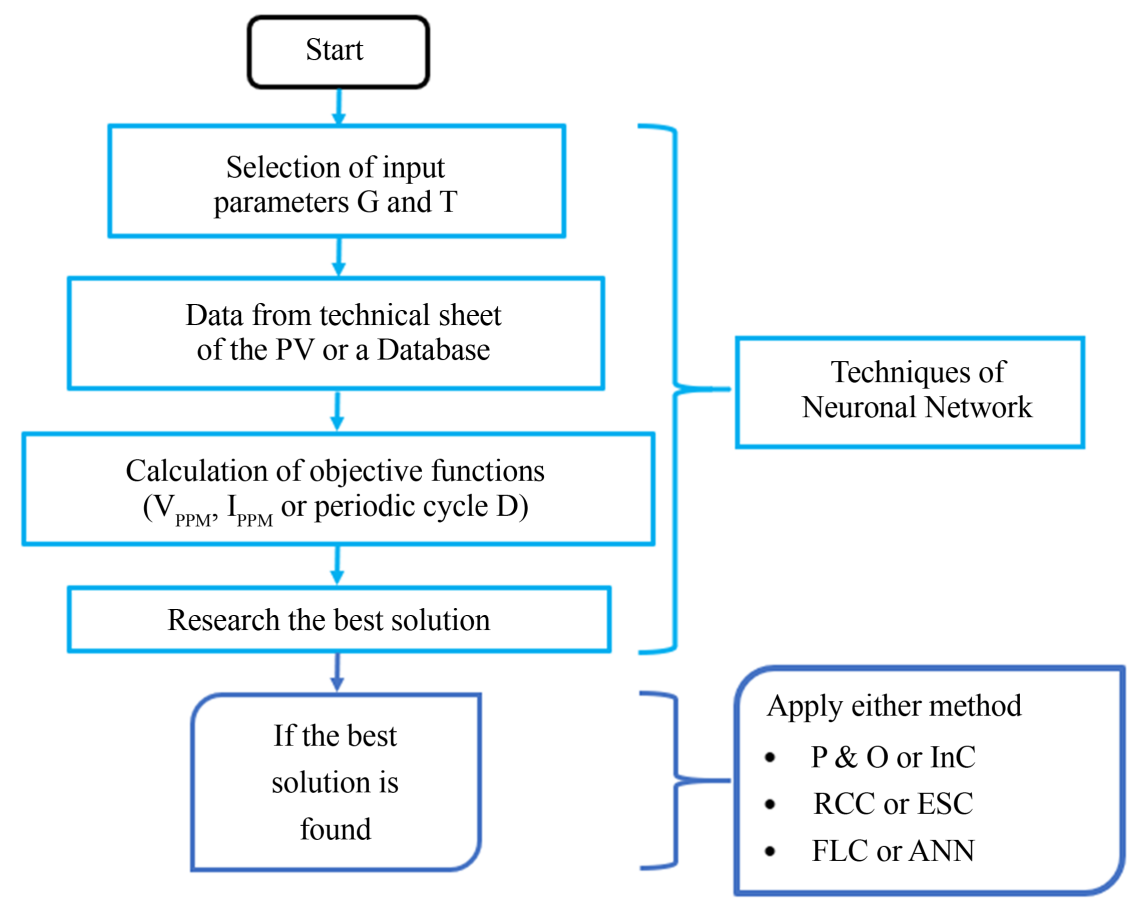

Figure 11. Structure of our proposed approach. 
The strength of ANNs in system identification and adaptive controller development makes them well suited for PV system applications such as maximum power point tracking. In engineering applications, a multi-layered perceptron network formed by the backpropagation method is the most widely used technique.

A non-recurring multilayer network has been developed in order to estimate the optimum voltage and current at the maximum power point (MPP) given the variation in irradiation and ambient temperature.

The architecture of the neural network adopted is made up of three layers. Input layers contain two neurons because they have two inputs (solar radiation and ambient temperature). The hidden layer consists of ten neurons; this number is selected following the execution of rules of thumb starting with a high number of neurons and eliminating those which are unnecessary provided network stability and output precision are achieved.

The output layer contains two neurons which correspond to the optimum voltage and current corresponding to the MPP. Figure 12 illustrates the architecture of this network. The training is done offline using the Matlab Toolbox and the MPPT controller offered in SIMULINK is shown in Figure 13.

The 8760 data collected from Mali's renewable energy agency were used for the training of the artificial neural networks. These measurements include solar irradiation and ambient temperature, which are taken from sunrise to sunset. The one-year database is used for the formation of two networks.

To ensure network accuracy, the network is continuously adjusted after each training by passing the test data set to the trained ANN model and recording the

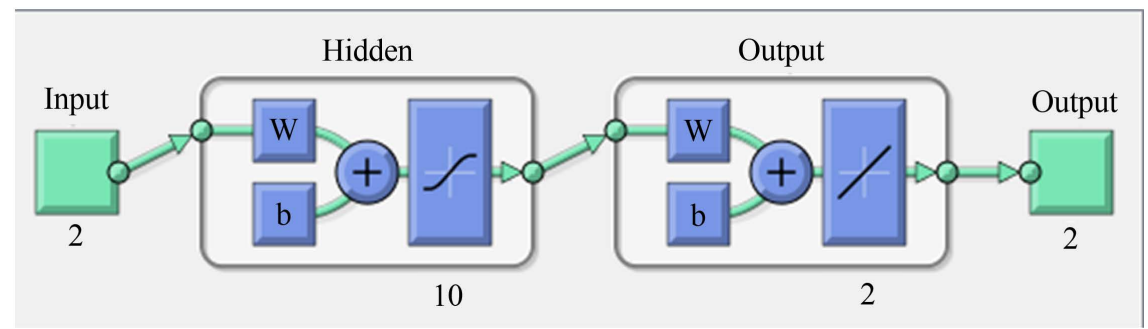

Figure 12. Architecture of the artificial neuron network under Matlab.

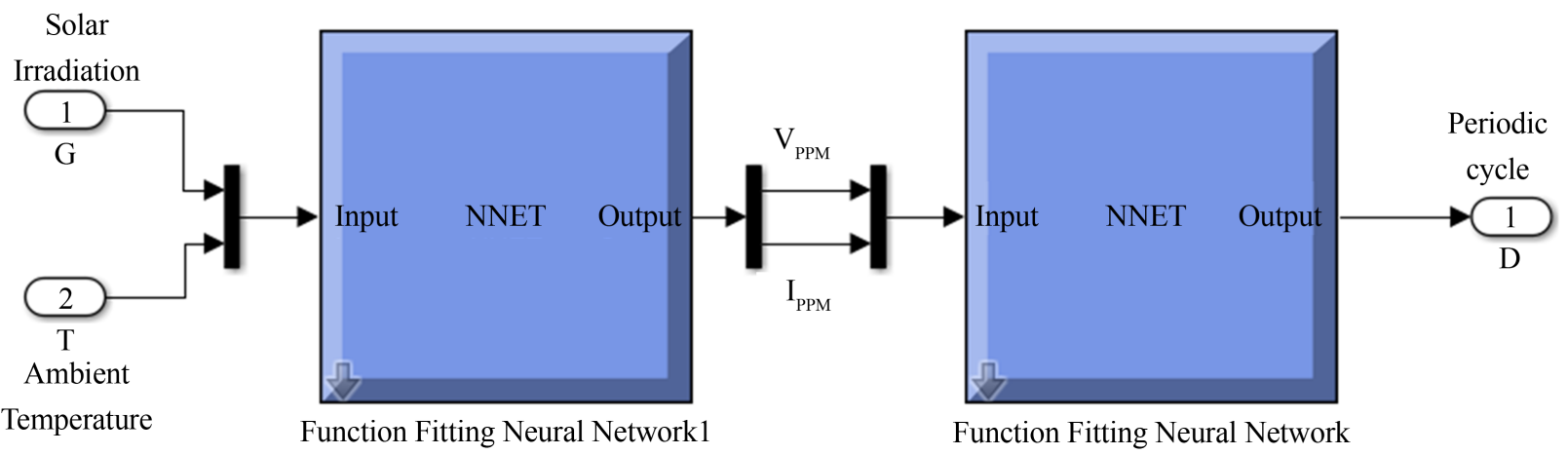

Figure 13. ANN hybrid controller proposed. 
results, then it is compared to measures. In the event of convergence, network performance is emulated by calculating a performance factor. Data validation is used as an additional check of model performance. If the performance of the network is completely correct on both the test sample and the validation sample, we can consider that the network is sufficiently adapted to generate the optimum voltage and current while being excited by inputs (G, T). The input variables of the second neural network are the optimum voltage and current estimated by the ANN model corresponding to a given solar radiation and to operating cell temperature conditions. The output variable is the corresponding duty cycle. Data for the inputs are collected from the same measurements as the first ANN model. The database is used to train the network and the others are used to verify the data.

The database will be randomly divided up in three kings of samples: data of training, data of validation and data of testing. Data of training are presented to the network during training and the network adjusted according to its error. Data of validation are used to measure network generalization halt training when generalization stops improving. Data of testing have no effect on training and so provide an independent measure of network performance during and after training. Usually, we set aside samples for validation at 15\%, 15\% for testing and $70 \%$ for training. So, 6132 samples were used to train networks, 1314 samples to validation and 1314 to testing.

Then these networks formed in offline mode are used in line mode (see Figure 14) in order to continue the MPP. The proposed hybrid neural network MPPT controller is tested and validated using the Matlab/Simulink modeling and simulation tool under different conditions. The Simulink model consisting of an MSX-60 module, a DC/DC converter driven by our hybrid model of neural networks and a load is shown in Figure 14.

\section{Simulation and Results}

The MATLAB/Simulink simulation tool is used for the complete simulation of the model produced. The MSX-60 PV module with the characteristic shown in

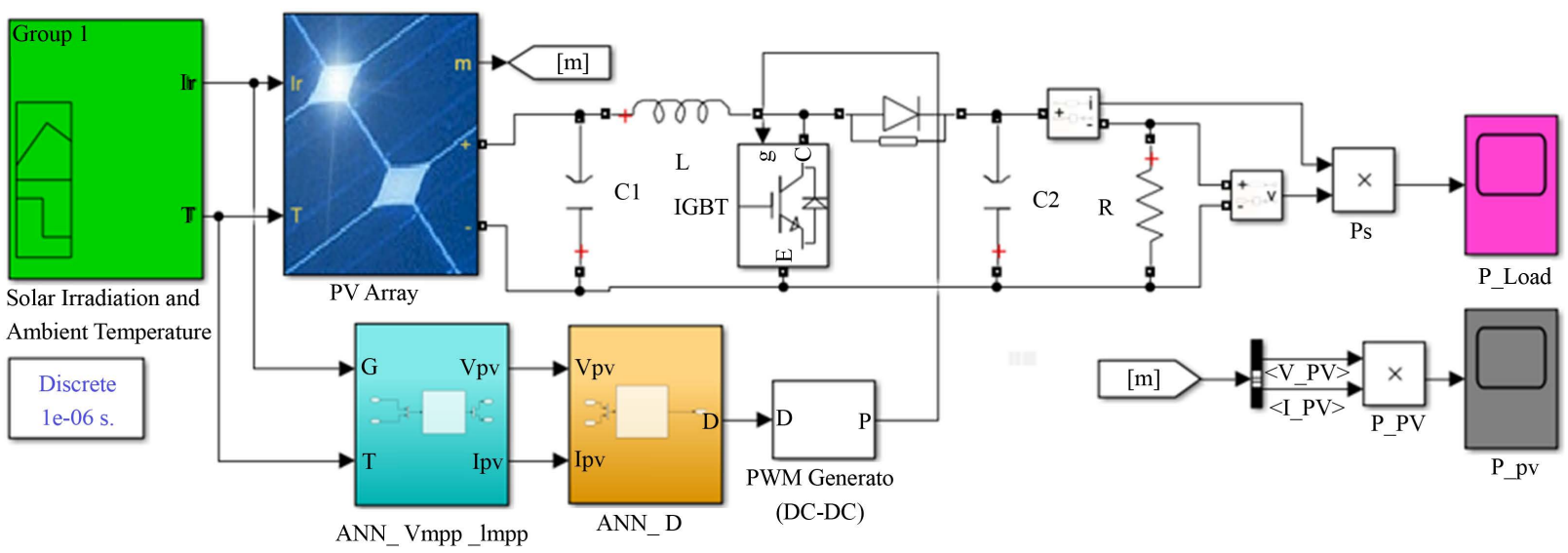

Figure 14. Block diagram of the hybrid controller of MPPT neuron networks under Matlab/Simulink. 
Table 2 was used. For the validation, our model was compared to the classical model of perturbation and observation ( $\mathrm{P} \& \mathrm{O})$.

The simulation is made on the conditions of variation of irradiation and at ambient temperature. Figure 15 and Figure 16 show the results obtained:

We can clearly see in Figure 15 among the two algorithms, that the algorithm of the hybrid system of neural networks gives values closer to the theoretical values and more precise. We also observe that the response time of RNA-hybrid is shorter than that of the perturbation and $\mathrm{P} \& \mathrm{O}$ observation. In addition, the proposed hybrid algorithm follows the MPP point more quickly during different conditions variations. The quality of the output power of the PV module for the RNA-hybrid approach shows a very good performance under sudden changes in solar irradiation in terms of: response time and overshoot (Figure 16). In addition, the $\mathrm{P} \& \mathrm{O}$ technique depends more on the temperature than the RNA-hybrid technique (Figure 16(a) (zone 1)).

Table 2. Characteristic of the MSX-60 PV module.

\begin{tabular}{cc}
\hline Parameters & Values \\
\hline $\mathrm{V}_{\mathrm{OC}}$ & $21.06 \mathrm{~V}$ \\
$\mathrm{I}_{\mathrm{SC}}$ & $3.80 \mathrm{~A}$ \\
Current at $\mathrm{P}_{\max }\left(\mathrm{I}_{\mathrm{MPP}}\right)$ & $3.80 \mathrm{~A}$ \\
Voltage at $\mathrm{P}_{\max }\left(\mathrm{V}_{\mathrm{MPP}}\right)$ & $17.10 \mathrm{~V}$ \\
Maximum power $\left(\mathrm{P}_{\mathrm{MPP}}\right)$ & $60.63 \mathrm{~W}$ \\
Temperature coefficient $\left(\mathrm{V}_{\mathrm{OC}}\right)\left(\mathrm{K}_{\mathrm{V}}\right)$ & $-0.084 \mathrm{~V} /{ }^{\circ} \mathrm{C}$ \\
Temperature coefficient $\left(\mathrm{I}_{\mathrm{SC}}\right)\left(\mathrm{K}_{\mathrm{I}}\right)$ & $3.3 \times 10^{-4} \mathrm{~A} /{ }^{\circ} \mathrm{C}$ \\
\hline
\end{tabular}
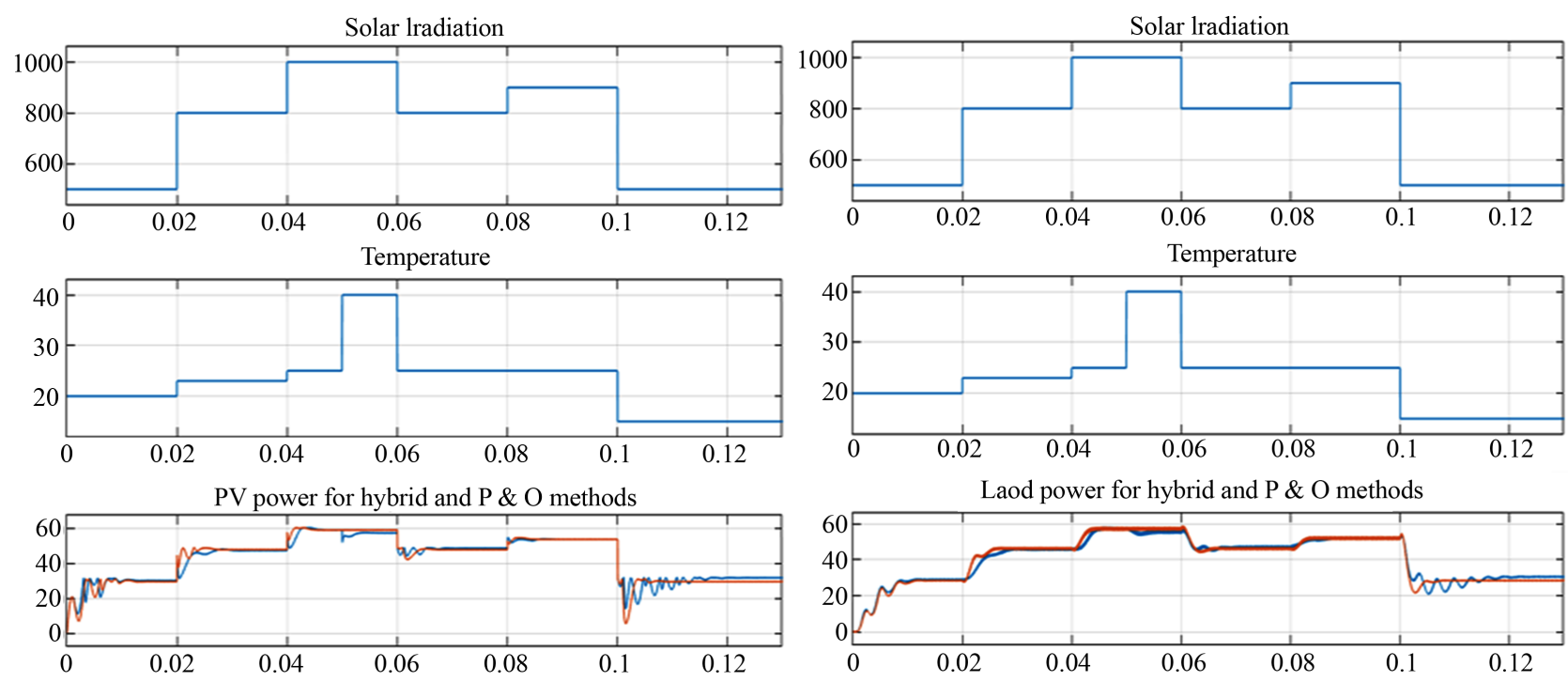

(a)

(b)

Figure 15. Output powers of the P\&O and RNA-hybrid controllers (a), their corresponding loads (b) under the conditions of irradiation and variable temperature. 


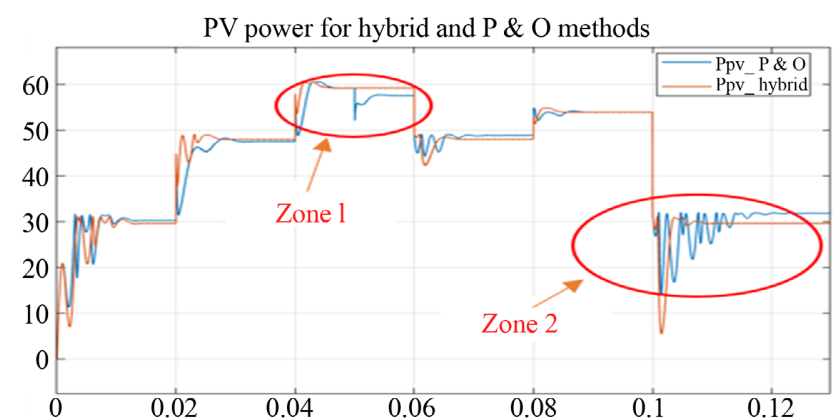

(a)

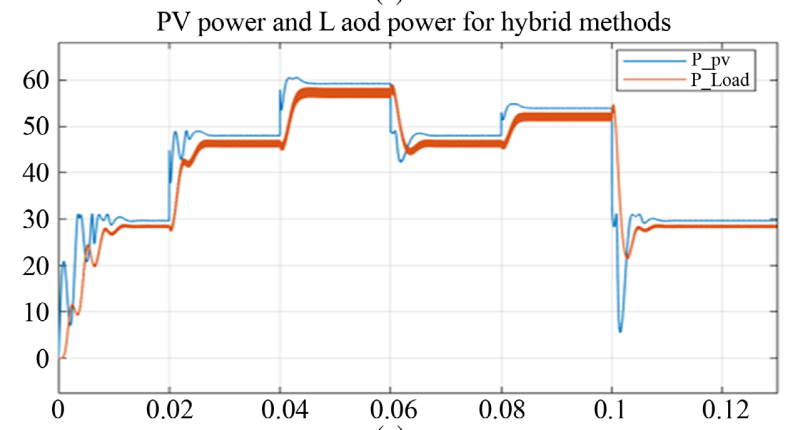

(c)

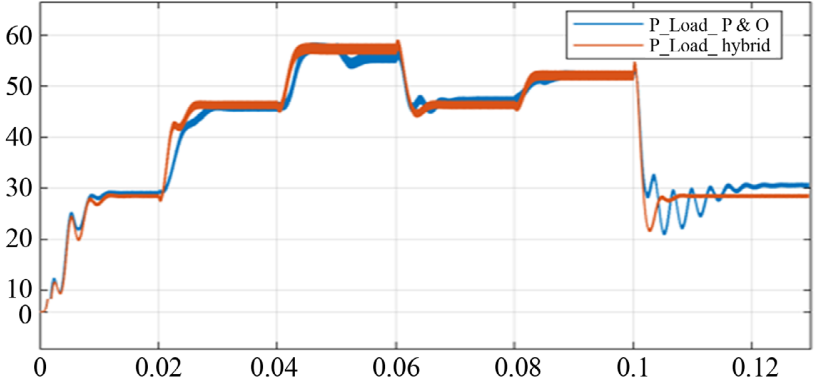

(b)

$\mathrm{PV}$ power and $\mathrm{L}$ aod power for $\mathrm{P} \& \mathrm{O}$ method

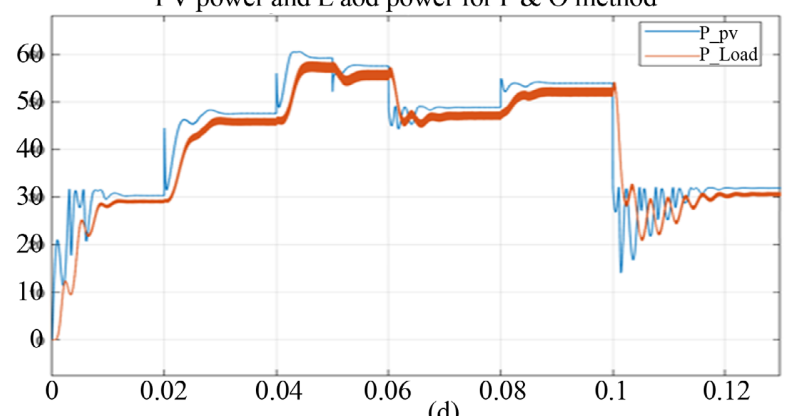

Figure 16. Different powers under the condition variations of solar irradiation and ambient temperature.

\section{Conclusions}

In the first part, we presented a study on the different maximum power point tracking methods carried out in the literature. We then highlighted the different limits of these techniques through a comparative study. In this work, the approach of maximum power point tracking based on hybrid neural networks was presented, as our contribution. The simulation is made on the conditions of variation of irradiation and ambient temperature. Figure 15 and Figure 16 illustrate the different results, we can clearly see in Figure 16 that among the two algorithms, the hybrid neural network system algorithm gives values closer to the theoretical values and more precise. We also find that the response time of RNA-hybrid is shorter than the Perturbation and observation P\&O. In addition, the proposed hybrid algorithm tracks the maximum power point more quickly during different conditions variations. The quality of the output power of the PV module for the ANN-hybrid approach exhibits very good performance in the event of a sudden change in solar irradiation in terms of: response time and overshoot (Figure 16). In addition, the $\mathrm{P} \& \mathrm{O}$ technique is more dependent on temperature than the ANN-hybrid technique (Figure 16(a) (zone 1)).

The results of this hybrid approach of neural networks are better compared to the classical method of perturbation and observation $\mathrm{P} \& \mathrm{O}$ in terms of response time, overshoots and rapid stabilization around the MPP point during sudden changes in solar irradiation and ambient temperature.

Thanks to more efficient conversion systems which aim to maximize the production of PV modules, hybrid photovoltaic systems coupled to the electricity grid are becoming more and more interesting but the management of the pro- 
duction of these photovoltaics poses enormous problems given its intermittent status. In perspective, we will see if it would be more advantageous to replace the second neural network with Adaptative Neuro-Fuzzy Inference (ANFIS) control to estimate the duty cycle, i.e., two MPPT methods will be hybridized for adjusting the duty cycle of the DC-DC converter switch to track the maximum power of a PV array.

\section{Conflicts of Interest}

The authors declare no conflicts of interest regarding the publication of this paper.

\section{References}

[1] Ahmed, J. and Salam, Z. (2016) A Modified P\&O Maximum Power Point Tracking Method with Reduced Steady-State Oscillation and Improved Tracking Efficiency. IEEE Transactions on Sustainable Energy, 7, 1506-1515. https://doi.org/10.1109/TSTE.2016.2568043

[2] Veerachary, M. and Shinoy, K.S. (2005) V²-Based Power Tracking for Nonlinear PV Sources. IEE Proceedings-Electric Power Applications, 152, 1263-1270. https://doi.org/10.1049/ip-epa:20045227

[3] Ricco, M., Manganiello, P., Petrone, G., Monmasson, E. and Spagnuolo, G. (2014) FPGA-Based Implementation of an Adaptive P\&O MPPT Controller for PV Applications. 2014 IEEE 23rd International Symposium on Industrial Electronics (ISIE), Istanbul, 1-4 June 2014, 1876-1881. https://doi.org/10.1109/ISIE.2014.6864901

[4] Kollimalla, S.K. and Mishra, M.K. (2014) Variable Perturbation Size Adaptive P\&O MPPT Algorithm for Sudden Changes in Irradiance. IEEE Transactions on Sustainable Energy, 5, 718-728. https://doi.org/10.1109/TSTE.2014.2300162

[5] Elgendy, M.A., Zahawi, B. and Atkinson, D.J. (2012) Assessment of the Incremental Conductance Maximum Power Point Tracking Algorithm. IEEE Transactions on Sustainable Energy, 4, 108-117. https://doi.org/10.1109/TSTE.2012.2202698

[6] Farhoodnea, M., Mohamed, A., Shareef, H. and Zayandehroodi, H. (2013) Optimum D-STATCOM Placement Using Firefly Algorithm for Power Quality Enhancement. 2013 IEEE 7 th International Power Engineering and Optimization Conference (PEOCO), Langkawi, 3-4 June 2013, 98-102.

https://doi.org/10.1109/PEOCO.2013.6564523

[7] Sera, D., Mathe, L., Kerekes, T., Spataru, S.V. and Teodorescu, R. (2013) On the Perturb-and-Observe and Incremental Conductance MPPT Methods for PV Systems. IEEE Journal of Photovoltaics, 3, 1070-1078. https://doi.org/10.1109/JPHOTOV.2013.2261118

[8] Ramasamy, A. and Vanitha, N.S. (2014) Maximum Power Tracking for PV Generating System Using Novel Optimized Fractional Order Open Circuit Voltage-FOINC Method. 2014 International Conference on Computer Communication and Informatics, Coimbatore, 3-5 January 2014, 1-6.

https://doi.org/10.1109/ICCCI.2014.6921842

[9] Afghoul, H., Krim, F., Chikouche, D. and Beddar, A. (2013) Tracking the Maximum Power from a PV Panels Using of Neuro-Fuzzy Controller. 2013 IEEE International Symposium on Industrial Electronics, Taipei, 28-31 May 2013, 1-6. https://doi.org/10.1109/ISIE.2013.6563734 
[10] Xu, W., Mu, C. and Jin, J. (2014) Novel Linear Iteration Maximum Power Point Tracking Algorithm for Photovoltaic Power Generation. IEEE Transactions on Applied Superconductivity, 24, 1-6. https://doi.org/10.1109/TASC.2014.2333534

[11] Safari, A. and Mekhilef, S. (2010) Simulation and Hardware Implementation of Incremental Conductance MPPT with Direct Control Method Using Cuk Converter. IEEE Transactions on Industrial Electronics, 58, 1154-1161. https://doi.org/10.1109/TIE.2010.2048834

[12] Moo, C.S. and Wu, G.B. (2014) Maximum Power Point Tracking with Ripple Current Orientation for Photovoltaic Applications. IEEE Journal of Emerging and Selected Topics in Power Electronics, 2, 842-848. https://doi.org/10.1109/JESTPE.2014.2328577

[13] Reisi, A.R., Moradi, M.H. and Jamasb, S. (2013) Classification and Comparison of Maximum Power Point Tracking Techniques for Photovoltaic System: A Review. Renewable and Sustainable Energy Reviews, 19, 433-443. https://doi.org/10.1016/j.rser.2012.11.052

[14] Malek, H. and Chen, Y.Q. (2014) A Single-Stage Three-Phase Grid-Connected Photovoltaic System with Fractional Order MPPT. 2014 IEEE Applied Power Electronics Conference and Exposition (APEC), Fort Worth, 16-20 March 2014, 1793-1798. https://doi.org/10.1109/APEC.2014.6803549

[15] Kim, K.A., Xu, C.Y., Jin, L. and Krein, P.T. (2013) A Dynamic Photovoltaic Model Incorporating Capacitive and Reverse-Bias Characteristics. IEEE Journal of Photovoltaics, 3, 1334-1341. https://doi.org/10.1109/JPHOTOV.2013.2276483

[16] Touré, A.F., Addouche, S.A., Danioko, F., Diourté, B. and Mhamedi, A.E. (2019) Hybrid Systems Optimization: Application to Hybrid Systems Photovoltaic Connected to Grid. A Mali Case Study. Sustainability, 11, Article No. 2356. https://doi.org/10.3390/su11082356

[17] Sefa, I., et al. (2015) Fuzzy PI Controlled Inverter for Grid Interactive Renewable Energy Systems. IET Renewable Power Generation, 9, 729-738. https://doi.org/10.1049/iet-rpg.2014.0404

[18] Toure, A.F., Danioko, F. and Diourte, B. (2021) Application of Artificial Neural Networks for Maximal Power Point Tracking. International Journal of Sustainable and Green Energy, 10, 40-46. https://doi.org/10.11648/j.ijrse.20211002.12

[19] Daraban, S., Petreus, D. and Morel, C. (2013) A Novel Global MPPT Based on Genetic Algorithms for Photovoltaic Systems under the Influence of Partial Shading. IECON 2013-39th Annual Conference of the IEEE Industrial Electronics Society, Vienna, 10-13 November 2013, 1490-1495. https://doi.org/10.1109/IECON.2013.6699353

[20] El Khateb, A., Abd Rahim, N., Selvaraj, J. and Uddin, M.N. (2014) Fuzzy-LogicController-Based SEPIC Converter for Maximum Power Point Tracking. IEEE Transactions on Industry Applications, 50, 2349-2358. https://doi.org/10.1109/TIA.2014.2298558

[21] Hua, C.C., Lin, J.R. and Shen, C.M. (1998) Implementation of a DSP-Controlled Photovoltaic System with Peak Power Tracking. IEEE Transactions on Industrial Electronics, 45, 99-107. https://doi.org/10.1109/41.661310

[22] Blaabjerg, F. and Ionel, D.M. (2017) Renewable Energy Devices and Systems with Simulations in MATLAB $^{\oplus}$ and ANSYS $^{\circledast}$. CRC Press. https://doi.org/10.1201/9781315367392

[23] Kordmahaleh, A.A., Naghashzadegan, M., Javaherdeh, K. and Khoshgoftar, M. (2017) Design of a 25 MWe Solar Thermal Power Plant in Iran with Using Parabolic 
trough Collectors and a Two-Tank Molten Salt Storage System. International Journal of Photoenergy, 2017, Article ID: 4210184.

https://doi.org/10.1155/2017/4210184

[24] Charfi, S. and Chaabene, M. (2014) Acomparative Study of MPPT Techniques for PV Systems. 2014 5th International Renewable Energy Congress (IREC), Hammamet, 25-27 March 2014, 1-6. https://doi.org/10.1109/IREC.2014.6827034 